\title{
Dynamic Analysis of Criminal Behavior: An Application of Empirical Mode Decomposition
}

\author{
Raphael Douglas de Freitas Lucena ${ }^{1}$, Rodolfo Ferreira Ribeiro Costa ${ }^{2}$, Ivan Castelar $^{3} \&$ \\ Francisco Soares de Lima $^{2}$ \\ ${ }^{1}$ Ph.D. Student in the Department of Economics of the Universidade Federal do Ceará, Fortaleza, CE, Brazil \\ ${ }^{2}$ Adjunct Professor in the Department of Economics of the Universidade do Estado do Rio Grande do Norte \\ (UERN). Mossoró, RN, Brazil \\ ${ }^{3}$ Department of Finance, Federal University of Ceará, Fortaleza, Ceará, Brazil \\ Correspondence: Ivan Castelar, Department of Finance, Federal University of Ceará, Fortaleza, Ceará, Brazil. \\ Tel: 55-85-3366-7751. E-mail: ivan@caen.ufc.br
}

Received: February 8, 2021

Accepted: March 11, 2021

Online Published: March 15, 2021

doi:10.5539/ijef.v13n4p47

URL: https://doi.org/10.5539/ijef.v13n4p47

\begin{abstract}
Our objective is to measure the permanent and transitory components of criminality in Brazilian states by using the methodology proposed by At and Chappe (2005). The empirical strategy used follows the Empirical Mode Decomposition method (EMD), proposed by Huang et al. (1998). Based on a sample collected using the Mortality Information System (SIM) from DATASUS, the decomposition process was carried out for the 27 Brazilian states from 1996 to 2015. The results of the decomposition for criminality show that the choice for crime occurs, for the largest part, due to permanent elements, which is a predictor of future crimes over time. The decomposition of criminality into these two types of components establishes some evidence regarding criminal behavior that can serve as reference for policy makers, since the implications of the results found raise questions about the policies to confront and reduce crime.
\end{abstract}

Keywords: time series, criminality, empirical mode decomposition, Brazilian States

JEL: C22, K14.

\section{Introduction}

Works on crime are relevant for their nature and the extent to which this issue touches the lives of people, as well as the development of countries since the negative implications of crime disproportionately affect individuals who are most vulnerable (Gramckow, Greene, Marshall, \& Barão, 2016).

Soares and Naritomi (2010) point out that the proportion of crimes is noticeably greater in the Latin American and the Caribbean (LAC) regions when compared to the rest of the world. Specifically in Brazil, the growing problem of crime is responsible for bringing insecurity and fear to the entire population. According to data from the DATASUS Mortality Information System (SIM), the homicide rate per 100,000 inhabitants grew by $14 \%$ between 1996 and 2015, with a large part of this growth occurring in regions where the crime was not considerable, as in the case of the North and the Northeast.

The research focused on the problem of crime usually approaches the determinants and the costs of crime to society through the cost-benefit analysis featured in Becker (1968), as can be seen in Fajnzylber, Lederman, and Loayza (1998); Araújo Junior and Fajnzylber (2010); Lisboa and Andrade (2000); Resende and Andrade (2011). These works analyze the effects on crime of socioeconomic variables such as income inequality, education, unemployment, urbanization etc. Also, other authors discuss the deterrent effects on crime, such as Lott Jr. (1992); Levitt (1995); Santos (2009); Justus, Kahn, and Cerqueira (2016).

However, these works use a traditional model of crime which does not take into account that individuals can perform a sequence of crimes, as this type of approach generally uses a static model. Thus, Oliveira (2012) argues that the expected utility increases with the repetition of crimes; and this, coupled with the fact that the costs of illicit activity grow at a lower rate, causes the gains in scale related to the recurrence of the criminal act to increase the welfare of the perpetrator. That is, when decision making, the individual would take into account the impact of 
the cost in the future by the option for criminal behavior at the present moment.

As a result, one can observe that there are dynamic effects that explain the choice of the criminal agent that is not taken into consideration by a static model. Among some works that use dynamic models, it is possible to mention Leung (1995); O'Flaherty (1998); Mocan, Billups, and Overland (2005); Lee and McCrary (2017).

Choosing to commit a crime reflects the state of nature in which the potential criminal is. Thus, it can be argued that a change in this state will result in alterations in the expected value of the crime, as there will be periods in which the agent will make the option to become a criminal, while in others that individual may abstain from illegal activities (At \& Chappe, 2005).

Therefore, considering the existence of components that are permanent (long term), transitory (short term), or both, criminality is rarely discussed in the literature. The identification of these components leads to the need for a more adequate approach to government policies since a structural problem cannot be dealt with only short-term measures.

In this sense, this work aims to identify the permanent and transitory components for a series of violent criminality in the states of Brazil. For that purpose, this approach follows the theoretical model proposed by At and Chappe (2005). In the empirical strategy, the Empirical Mode Decomposition - EMD method, proposed by Huang, Shen, Long, Wu, Shih, Zheng, and Liu (1998) will be used. The goal is to find evidence as to which aspects of crime dynamics can be composed of structural issues that require a greater effort for remediation or solution.

In addition to this introductory section, this work features four more sections. The next two sections present the intertemporal model of crime choice and the empirical strategy is discussed. Section four features the empirical results for the decomposition of violent crime. Lastly, the concluding remarks are presented.

\section{Theoretical Model of Crime: An Intertemporal Approach to the Individual's Choice}

In the model proposed by At and Chappe (2005), each individual is identified by the benefit they would achieve by making the choice, $b \in[0, B]$. The option for the crime generates damages, $h$, and by definition, $h<B$; in other words, it is socially acceptable some type of offense. Moreover, the model has an infinite number of periods, $t=0,1, \ldots$ and a continuous discount rate $\rho$. At $t=0$, individuals must decide whether to commit or abstain from crime. Individuals who commit the crime are subject to a probability of being detected, $p$, and fine, $f$. If they are caught, the game ends. However, if individuals decide to postpone the option for crime, then the benefit increases at the $\alpha$ rate, that is, it becomes $b e^{(\alpha-\rho) t}$.

Considering first the decision of individuals to commit the crime immediately, or later, the strategies of the individuals are clearly outlined as follows. First, individuals can decide not to commit the crime. The expected return is then zero. Second, individuals can decide to commit the crime at $t=0$. In this case, the expected result is:

$$
F^{0}=b-p f
$$

Third, individuals can decide to wait. Therefore, this strategy generates an expected return:

$$
F^{t}=b e^{(\alpha-\rho)}-p f e^{-\rho t}
$$

Note that when $\alpha>\rho$, waiting longer to commit the crime would always be a better policy and the optimum would not exist. Consequently, from now on, the case is considered when $\alpha<\rho$. There will be a critical benefit above which individuals will commit the crime immediately, and below which they will commit the crime later. The critical benefit is defined by the probability of detection, the sanction level, and the growth rates, which defines the critical benefit as $\bar{b}=\frac{\rho}{\rho-\alpha} p f$. If $b \in(0, \bar{b})$ individuals commit the crime in $T^{*}=\frac{1}{\alpha} \log \left[\frac{\rho p f}{(\rho-\alpha) b}\right]>$ 0 . If $b \in[\bar{b},+\infty)$ individuals commit the crime at $t=0$.

If the benefit is greater than the critical benefit $\bar{b}$, then it is ideal to commit the crime immediately, since the benefit to postponing is less than its cost due to the discount, $\rho$. If the benefit is less than the critical benefit $\bar{b}$, then individuals should expect to increase their benefit sufficiently. The discounted benefit increases by one factor $e^{(\alpha-\rho) t}$, while the expected discounted penalty increases by a smaller factor $e^{-\rho t}$. In other words, there are situations in which it is preferable to postpone the crime, even if the gain from the option exceeds the punishment expected in the first period.

The choice for the crime can take a level of volatility that would last for a certain number of periods and then 
return to its trajectory. In other words, transitory choices are made according to the state of nature in the period of decision making, given that at some point they may dissipate, leaving a structural component (trend) that is perpetuated throughout the periods.

\section{Empirical Strategy}

As could be seen above, the action of committing or abstaining from a crime is considered as an intertemporal process of choice, where the main objective of the criminal agent is to maximize the expected return of the criminal act. This decision-making process, therefore, can be seen as a volatile element, which changes according to the current state of nature. Thus, criminal behavior can be altered by permanent or transitory conditions, which modify an individual's decision to commit a crime.

The condition which is always present and motivates the individual to commit a crime, regardless of the state of nature in which that person is in, is defined as the permanent factor. On the other hand, the condition for criminal behavior that occurs in some periods, but not in others (i.e. anticipating or abstaining from the option of committing a crime), can be defined as fluctuations around a trend, a transitory factor.

The decomposition of the criminality series can be obtained following the recommendations of Engelen (2004) and At and Chappe (2005), where the decision to commit the criminal act can be implemented at different times in the life cycle of an agent (for example, conditions for deciding on criminal behavior is more frequent during the juvenile phase). According to Gottfredson and Hirschi (1986), the chance of committing a crime usually increases until the end of adolescence, and then decreases. Furthermore, Elliott, Huizinga, and Ageton (1985), point out that it is in this stage of life where the highest rate of antisocial behavior is observed.

The understanding that this decision obeys cyclical movements and, thus, may reflect higher intensities according to the state of nature, implies that a series of criminality presents a composition distributed in elements in which the proportions fluctuate along with its trend. This condition is considered in this work, where the specific components for the series of criminality will be defined and empirically identified.

The time series decomposition in this work will follow the proposal of (Huang et al., 1998). The Hilbert-Huang Transform (HHT) is a method that decomposes, through the Empirical Mode Decomposition (EMD), the signal for a given time series in Intrinsic Mode Functions (IMFs). The EMD is a method that can be applied to non-stationary and non-linear data, ensuring that this method obtains an advantage over other methods. Kožić and Sever (2014) point out some advantages and limitations that are related to the EMD technique. One of the advantages is the fact that the technique is self-adaptive, allowing the data to respond to its characteristics, enabling a high degree of clarity, transparency, and intuition; while one of the limitations is the lack of an adequate theoretical basis.

\subsection{Empirical Mode Decomposition}

The Empirical Mode Decomposition is a method that empirically identifies all the behavior of intrinsic oscillations through the temporal characteristics of the signal and, subsequently, decomposes the series accordingly. The calculation presented by Huang et al. (1998) consists of the creation of an envelope defined by local maxima and minima of a finite set of oscillations and subsequent subtraction of the average of those envelopes from the initial set. Unlike the Fourier method and wavelets, EMD does not require any convolution of the signal with a predefined function, and its decomposition process is entirely data-driven.

Each oscillation is derived from the data and is referred to as an IMF. These functions are called intrinsic because each represents the signal change in the time series. An IMF must meet the following conditions:

1). The number of extremes and the number of crossings through the origin must be equal or differ by a maximum of 1 .

2). At any point, the average of the envelopes defined by local maxima and local minima must be zero.

IMFs are obtained through a process that makes use of local extremes to remove oscillations, starting with those most frequent. Thus, given a time series $x(t), t=1,2, \ldots, T$, the process decomposes it into a finite number of intrinsic mode functions represented by $I M F_{k}(t), k=1, \ldots, \mathrm{n}$, plus one residue $r_{n}(t)$. At the end of the decomposition process, the original time series can be reconstructed as:

$$
x(t)=\sum_{k=1}^{n} I M F_{k}(t)+r_{n}(t)
$$

with $r_{n}(t)$ being the permanent component of the series.

The systematic method for extracting intrinsic functions is called the sifting process. This process can be seen in Figure 1 below. 
The decomposition process comprises the following steps:

1). Initialize the original time series for the residue $r_{0}(t)=x(t)$ and set the IMF index $\mathrm{k}=1$.

2). Extract the nth IMF in the following way: a) Initialize $h_{0}(t)=r_{k-1}(t)$ and the iteration count $\mathrm{i}=1$; b) Find local maxima and local minima of $h_{i-1}(t)$ (Figure 1, (a)); b) create a superior and an inferior envelope, $\mathrm{E}_{\mathrm{u}}(\mathrm{t})$ and $\mathrm{E}_{\mathrm{l}}(\mathrm{t})$, by interpolation among the local maxima and local minima, respectively, (figure 1 (b)); d) Calculate the average of both envelopes a $m_{i-1}(t)=\left[E_{u}(t)+E_{l}(t)\right] / 2$, obtaining a lower frequency component than the original series (figure $1(\mathrm{c})$ ); e) Subtract the envelope of the input time series, thereby obtaining the oscillatory component $h_{i}(t)=h_{i-1}(t)-m_{i-1}(t)$ (figure $1(\mathrm{~d})$ ); f) Verify that it meets the IMF's conditions: If $h_{i}(t)$ does not meet the IMF's conditions, increase $i=i+1$ and repeat the step sifting process (b); if $h_{i}(t)$ meets the IMF's conditions, define $I M F_{k}(t)=h_{i}$ and define $r_{k}(t)=r_{k-1}(t)-I M F_{k}(t)$.

$3)$. When the residue $r_{k}(t)$ is a constant or a monotonic slope that contains only one extreme, the process is interrupted; otherwise, the decomposition of step 2 continues, defining $k=k+1$.

(a)

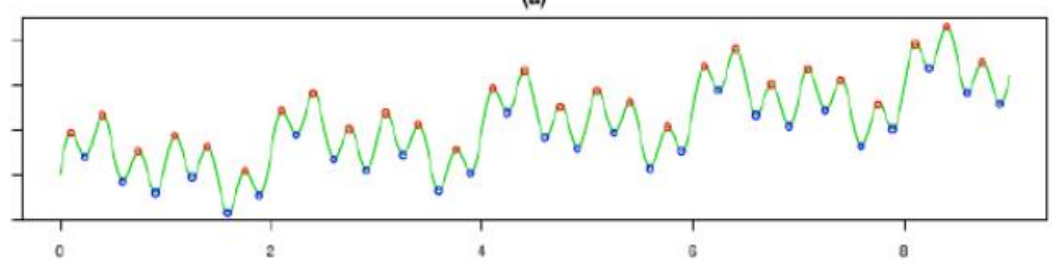

(b)

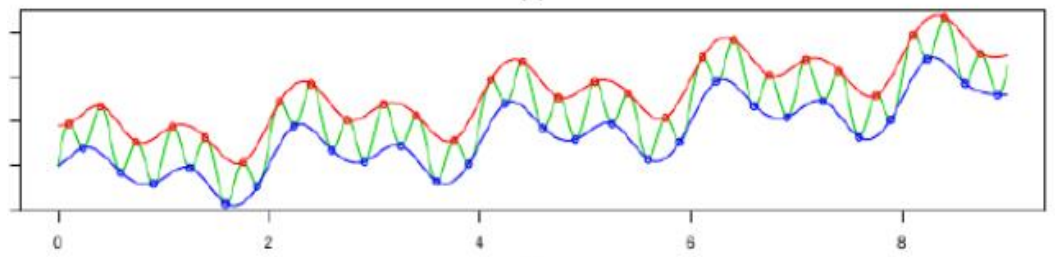

(c)

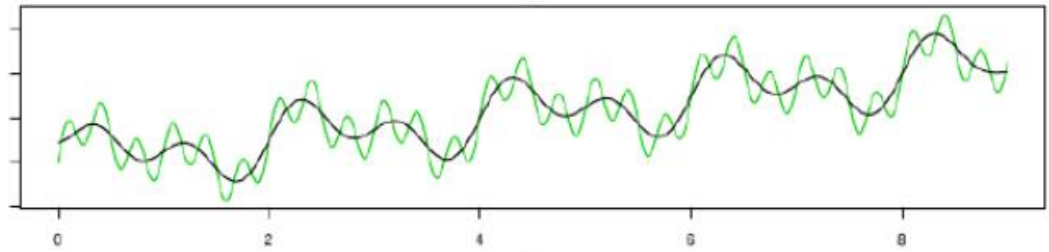

(d)

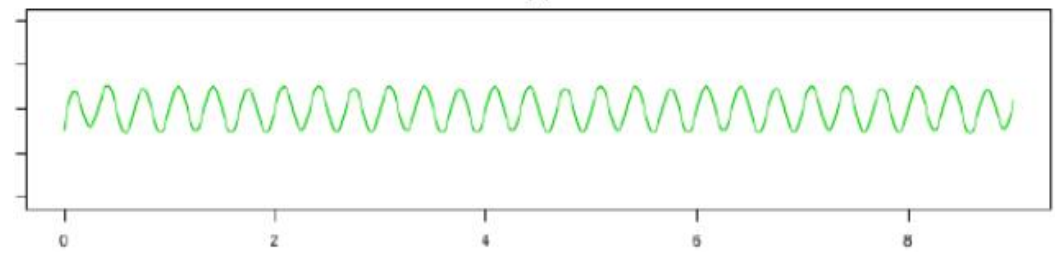

Figure 1. Illustration of the selection process (sifting)

Source: Adapted from Kim and Oh (2009).

As shown in Figure 1, the selection algorithm identifies and extracts the oscillatory component with the highest local frequency in the data, leaving a partial residue. The successive application of the algorithm on the sequence of partial residues completely decomposes the time series into a set of IMFs plus one residue, represented as:

$$
x_{t}=\sum_{i=1}^{k} C_{i}(t)+r(t)
$$

Where $C_{i}(t)$ are the intrinsic mode fuctions and $r(t)=x_{t}-\sum_{i=1}^{k} C_{i}(t)$ is the residue, and $\mathrm{k}$ is the number of extracted IMFs.

Equation (4) shows that a given time series, $x_{t}$, can be divided into two components: $C_{i}(t)$ is the component of the criminal act that is created in each period, being understood as a short-term element; $r(t)$ corresponding to the part of the crime that is passed on for each period, which is the structural component of the series. It is believed that the first component is the deviation from the permanent component; that is, the fraction of crime that is generated in the short term and that dissipates itself over time. The second component, therefore, would be 
the core of the series, the portion that persists over time and, for that reason, must be addressed through medium and long-term policies.

It is worth mentioning that a measure of transitory/permanent proportion will be presented with the results of the decomposition. When such an index is less than 1, the permanent component is more important, and when it approaches 1 , both are equally important.

\subsection{Database}

To measure the permanent and transitory components of crime, data on the homicide rate per 100 thousand inhabitants were used. These data were collected from the DATASUS Mortality Information System (SIM). The decomposition process for the 27 Brazilian states was carried out individually, from 1996 to 2015.

\section{Results of Decomposition for Crime}

This subsection presents information about which states had a greater permanent or transitory component and how these respective components behave over time. The results of the decomposition process for the Brazilian states are featured in Table 1 below.

For the permanent component of criminality, it can be observed that the State of Espírito Santo presented an average of 49.66, the highest among the other states analyzed. Also, its maximum value of 52.78 occurred in 2005, while the minimum of 45.81 was recorded in 2015. Nevertheless, it is noticed that the Southeast and Northeast regions of the country have the four highest averages of the permanent component, with Espírito Santo presenting a value of 49.66, Pernambuco 48.49, Alagoas 45.52, and Rio de Janeiro 43.60.

Table 1. Descriptive statistics of the decomposition results of the permanent and transitory components of crime

\begin{tabular}{|c|c|c|c|c|c|c|c|c|}
\hline & Permanent & Max & Min & Deviation.P & Transitory & Max & Min & Deviation.P \\
\hline North & 28.02 & 35.19 & 23.74 & 3.24 & 2.34 & 5.27 & 1.09 & 1.03 \\
\hline RO & 34.16 & 39.18 & 26.73 & 3.68 & 2.42 & 3.74 & 0.20 & 0.92 \\
\hline $\mathrm{AC}$ & 21.90 & 25.58 & 19.40 & 2.35 & 2.59 & 9.91 & 0.10 & 2.32 \\
\hline $\mathrm{AM}$ & 24.31 & 36.62 & 17.94 & 7.18 & 1.51 & 4.27 & 0.22 & 1.32 \\
\hline $\mathrm{RR}$ & 33.86 & 46.09 & 23.50 & 8.04 & 4.40 & 11.90 & 0.08 & 3.60 \\
\hline PA & 28.30 & 44.11 & 11.11 & 13.31 & 1.52 & 4.54 & 0.07 & 1.11 \\
\hline AP & 34.76 & 37.76 & 32.31 & 1.96 & 2.51 & 6.51 & 0.05 & 1.94 \\
\hline TO & 18.86 & 28.98 & 9.47 & 5.22 & 1.45 & 2.76 & 0.03 & 0.80 \\
\hline Northeast & 27.85 & 41.94 & 16.41 & 9.25 & 1.99 & 2.65 & 1.06 & 0.45 \\
\hline MA & 16.71 & 35.71 & 4.68 & 9.93 & 0.83 & 2.03 & 0.18 & 0.47 \\
\hline PI & 12.20 & 19.23 & 6.87 & 4.71 & 1.94 & 3.57 & 0.28 & 0.82 \\
\hline $\mathrm{CE}$ & 26.15 & 49.61 & 13.03 & 12.05 & 1.38 & 3.66 & 0.07 & 1.12 \\
\hline $\mathrm{RN}$ & 20.52 & 44.50 & 7.41 & 12.95 & 1.65 & 3.62 & 0.02 & 1.03 \\
\hline PB & 25.45 & 41.71 & 12.87 & 10.85 & 0.96 & 2.27 & 0.10 & 0.54 \\
\hline $\mathrm{PE}$ & 48.49 & 58.22 & 38.99 & 7.02 & 3.01 & 7.14 & 0.20 & 2.12 \\
\hline $\mathrm{AL}$ & 45.52 & 68.25 & 23.64 & 17.63 & 2.54 & 4.73 & 0.04 & 1.63 \\
\hline SE & 31.14 & 50.62 & 9.46 & 11.63 & 3.93 & 7.12 & 0.49 & 2.06 \\
\hline $\mathrm{BA}$ & 24.49 & 41.27 & 10.18 & 12.44 & 1.66 & 4.20 & 0.07 & 1.15 \\
\hline Southeast & 34.18 & 39.34 & 27.01 & 4.85 & 2.53 & 3.98 & 1.52 & 0.75 \\
\hline MG & 17.74 & 22.92 & 7.19 & 5.46 & 1.54 & 4.41 & 0.16 & 1.37 \\
\hline ES & 49.66 & 52.78 & 45.81 & 2.36 & 3.75 & 10.70 & 0.00 & 2.73 \\
\hline RJ & 43.60 & 58.09 & 27.32 & 11.25 & 2.23 & 5.07 & 0.06 & 1.53 \\
\hline SP & 25.71 & 41.50 & 10.91 & 12.56 & 2.59 & 5.28 & 1.00 & 1.25 \\
\hline South & 18.60 & 21.81 & 12.62 & 3.33 & 0.82 & 1.95 & 0.39 & 0.35 \\
\hline PR & 25.92 & 32.82 & 14.50 & 6.07 & 0.98 & 2.98 & 0.05 & 0.74 \\
\hline SC & 10.80 & 12.78 & 7.70 & 1.95 & 0.59 & 1.42 & 0.00 & 0.39 \\
\hline $\mathrm{RS}$ & 19.07 & 24.56 & 15.67 & 2.60 & 0.89 & 2.16 & 0.05 & 0.53 \\
\hline Center-West & 31.86 & 34.66 & 30.17 & 1.46 & 1.75 & 2.67 & 0.86 & 0.51 \\
\hline MS & 29.68 & 37.43 & 23.80 & 3.35 & 1.47 & 4.63 & 0.15 & 1.21 \\
\hline MT & 34.86 & 37.86 & 32.61 & 1.66 & 2.07 & 7.32 & 0.26 & 1.93 \\
\hline GO & 27.84 & 44.65 & 13.71 & 10.18 & 1.16 & 2.27 & 0.17 & 0.60 \\
\hline DF & 35.05 & 37.08 & 28.61 & 2.33 & 2.31 & 4.72 & 0.38 & 1.35 \\
\hline BR & 28.40 & 34.13 & 23.51 & 3.68 & 2.00 & 2.74 & 1.44 & 0.36 \\
\hline
\end{tabular}


Regarding the oscillations that occur around the choices that change over time, it is possible to note that, on average, the largest transitory component corresponds to the State of Roraima, with a value of 4.40. This state reached, in 1999, a maximum of 11.90 for the transitional component, with a minimum of 0.08 in 2010 . This result indicates that the expected return on crime changes over the periods in higher proportion in the state of Roraima, which may be above the critical benefit at times, while in others, it is below. This is similar to the model proposed by At and Chappe (2005), where the choice to postpone a crime can be optimal, given that the benefit of waiting for increases sufficiently in the future.

Results of the transitory/permanent ratio are shown in Figure 2 below. As discussed in the review of the theoretical model, there are periods when the agent can make the option for criminal activity, while in others the individual may abstain, due to factors that can change the economic calculation and, consequently, the expected crime value (At \& Chappe, 2005). In this regard, Figure 2 displays the relative importance of the permanent and transitory component in the criminality of Brazilian states.

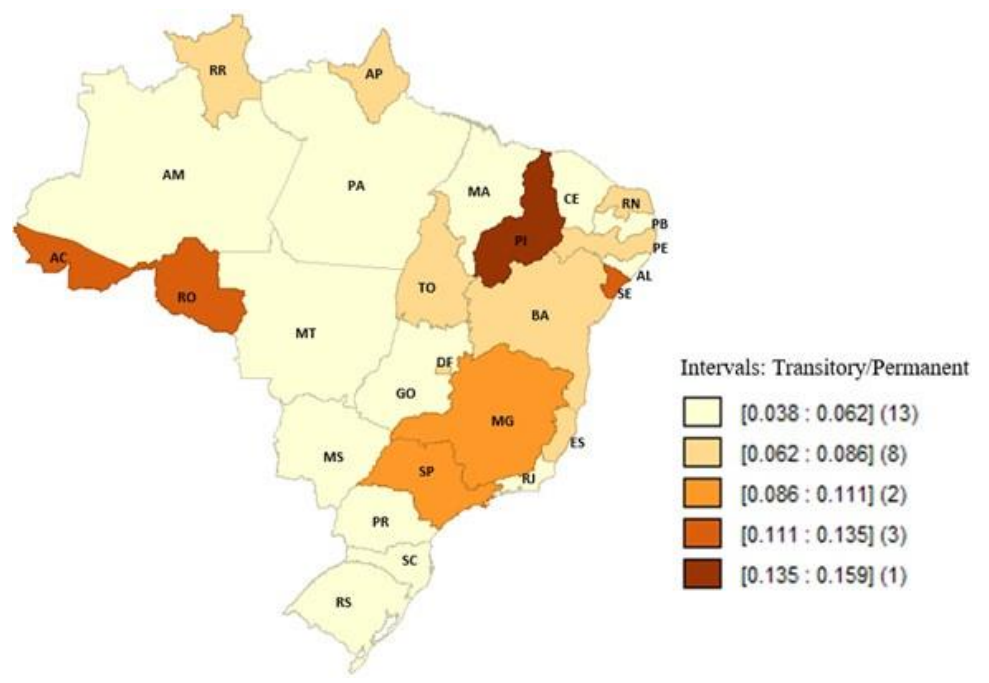

Figure 2. Map of the proportion between the transitory and permanent components of the homicide rate per 100 thousand inhabitants for the Brazilian states

It is possible to note that the permanent component represents the largest portion of the decomposition, with Paraíba and Paraná featuring a value of 0.038, Goiás with 0.042, the Rio Grande do Sul featuring 0.047, Mato Grosso do Sul 0.049 and Maranhão with 0.050 , being among the lowest calculated values.

However, some states have, in relative terms, a transitory component of greater prominence, as in the case of Piauí, with a value of 0.159 , Rondônia, with 0.130 , Sergipe, with 0.126 , Acre, with 0.118 , São Paulo, featuring 0.101, and Minas Gerais, with 0.087.

Figure 3 features the first ten states that had a growth in the permanent component. Except for Minas Gerais, $188 \%$, and Goiás, $201 \%$, all the other states are located in the North and Northeast regions of the country, with an emphasis on Sergipe, 435\%, Maranhão, 380\%, Pará, 287\%, and Rio Grande do Norte, $282 \%$.

Although the trajectory of the permanent component overtime is increasing for most states, some of those states are going in the opposite direction, even if in a smaller proportion, with an emphasis on the state of São Paulo, $-66 \%$, Rio de Janeiro, $-53 \%$, Mato Grosso do Sul, -36\%, and Distrito Federal, $-22 \%$.

These results present evidence that has not been widely discussed in the literature. The permanent component of crime is that part of the individual's choice that does not change over time, which_means that, for states where there is a positive variation in the permanent component, long term policies may be more appropriate for a consistent decrease in the homicide rate, so that its trajectory may be altered. On the other hand, the negative variation observed in some states possibly suggests that a combination of long and short-term policies, such as firearms control, demographic control, and improvements in the job market, may have contribu0t0ed to reverse the growth trend. 
Permanent

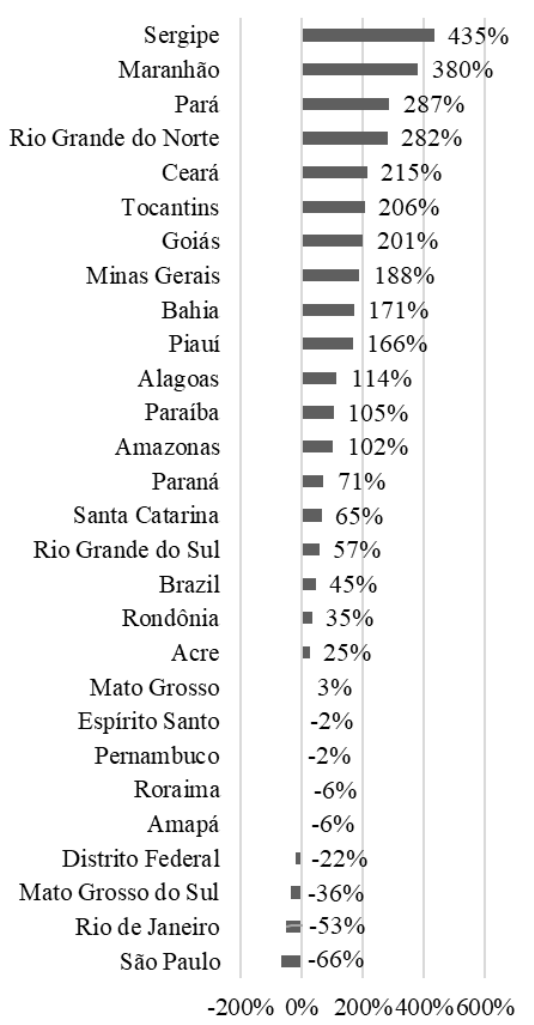

Transitory

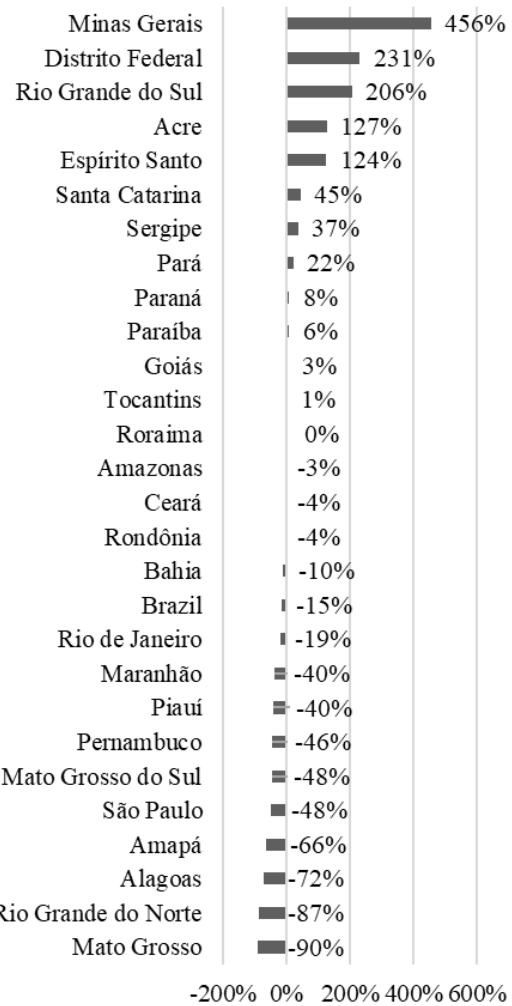

Figure 3. Variation of permanent and transitory components, by State (1996/2015)

Based on the panorama presented in Figure 3, it is possible to build a ranking to identify the direction of the homicide rate, depending on the variation in the importance of the permanent and transitory component of crime for each state.

When analyzing Figure 4, it is possible to notice that eight states had an increase in the transitory/permanent ratio, namely: Distrito Federal, 323\%, Espírito Santo, 129\%, Rio Grande do Sul, 95\%, Minas Gerais ,93\%, Acre, $81 \%$, Rio de Janeiro, $72 \%$, São Paulo, 51\%, and Roraima, $6 \%$.

Furthermore, there is a noteworthy heterogeneity to variations in the homicide rates. Distrito Federal, Espírito Santo, Rio de Janeiro, São Paulo, and Roraima, had decreases of $-28 \%,-14 \%$, $-52 \%$, $-68 \%$, and $-5 \%$, respectively, in homicide rates. However, Rio Grande do Sul, Minas Gerais, and Acre registered an increase of $70 \%, 194 \%$, and $29 \%$.

Another relevant point is that a large part of the states that had a reduction in the transitory/permanent ratio is in the Northeast region of the country, the others being in the North and Center-West regions: the Rio Grande do Norte,-97\%, Mato Grosso, -90\%, Maranhão, -87\%, Alagoas, -87\%, Piauí, -78\%, Sergipe, $-74 \%$, Ceará, $-70 \%$, Pará, $-68 \%$, Tocantins, $-67 \%$ and Bahia, $-67 \%$.

For the states that show negative variation in the proportion measure, it is possible to see in Figure 4 that there was an increase in homicide rates over the periods analyzed, except for the states of Amapá, -14\% and Mato Grosso do Sul, $-36 \%$, the other states featuring an increase, Rio Grande do Norte, with 384\%, Mato Grosso, 26\%, Maranhão, 426\%, Alagoas, 84\%, Piauí, 340\%, Sergipe, 294\%, Ceará, 261\%, Pará, 261\%, Tocantins, 160\% and Bahia, $153 \%$. 


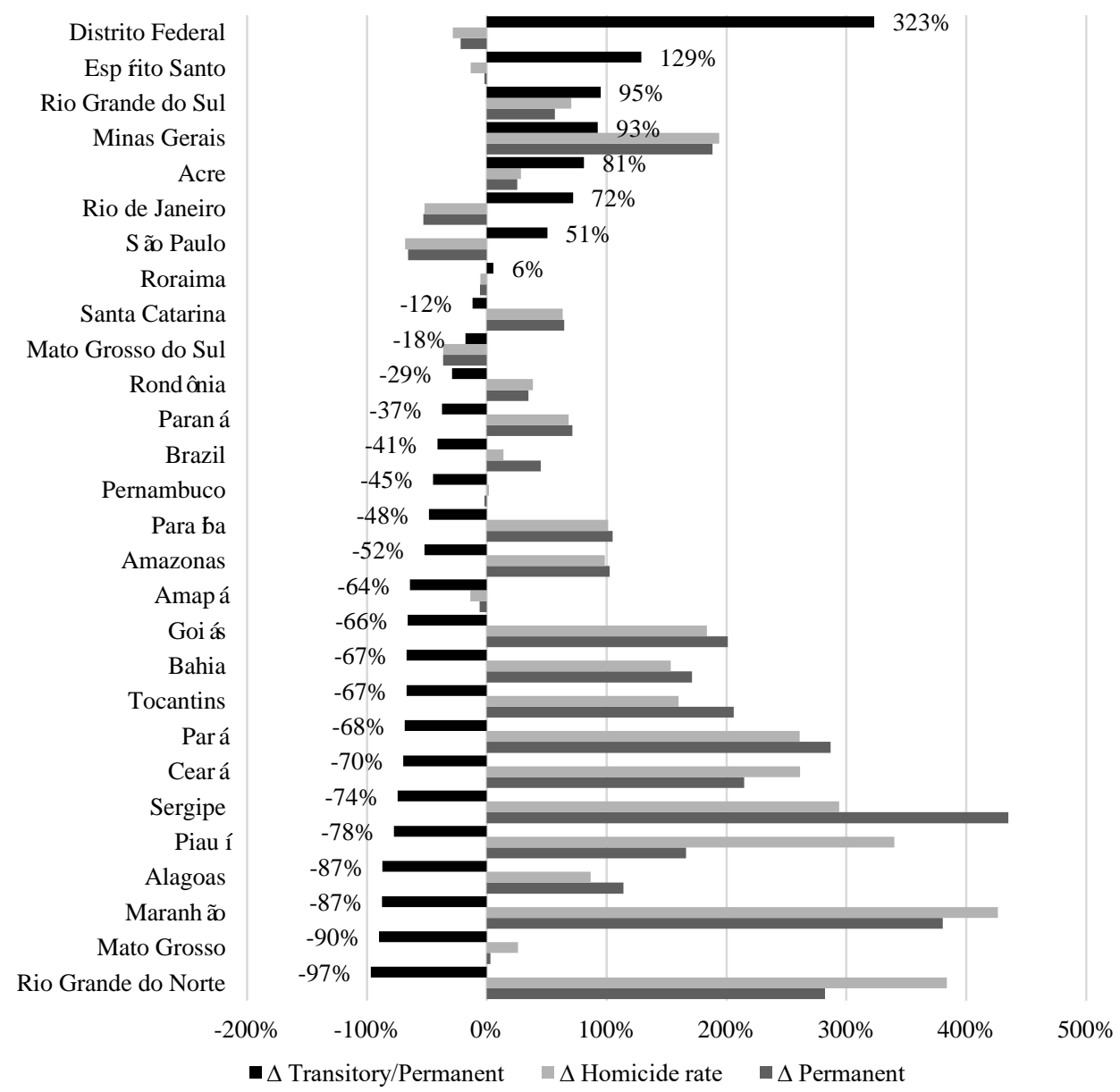

Figure 4. Rank by State of the variation of the transitional/permanent measure for crime (1996/2015)

Thus, the literature highlights that structural factors in an individual's life, such as income per capita, income inequality, education, family structure, among others, can permanently alter the economic calculation when deciding on opting to commit criminal activities because factors such as these are related to increases in the opportunity cost of committing a crime (Preston, 1982; Fajnzylber, Lederman, \& Loayza, 1998).

Transitory elements, which are occasional changes in the opportunity cost and which cause the decision for committing a crime to be postponed, are associated with the deterrence effect. These elements can be, for example, an ostensive patrolling action or the use of cameras for monitoring streets. According to Levitt (1995), depending on the critical situation of each state, the deterrence effect can be used as an emergency and quick combat measure. Still regarding this effect, Engelen (2014) argues that the increase in these costs for the criminal agent may not be permanent, and the decision to abstain from committing a crime simply represents a postponement of this decision until the ideal moment.

The decomposition of crime into permanent and transitory elements is, thus, relevant for policymakers, as the implications of the results achieved by the decomposition raise questions about the policies to confront and reduce crime. Through the use of information from different compositions of choices presented for the Brazilian states, it is possible to discuss and elaborate a political program to fight crime more adequately, directing financial and human resources in accordance with the nature of the problem.

\section{Conclusion}

This work analyzed the social problem of criminality through a time series approach. The objective was to decompose the permanent and transitory components of the crime rate to understand the formation of the dynamic process of choice for the option of committing a criminal act (At \& Chappe, 2005). The empirical strategy followed the EMD method of (Huang et al., 1998), performing the decomposition for each Brazilian state from 1997 to 2015. 
Regarding the results of the decomposition, it was found that the choice to commit a crime occurs, to a greater extent, on a permanent basis, and that this component had a negative variation in the Southeast region of Brazil, while in the Northeast region there was an increase. The result that the permanent component prevails over the transitory, paired with the fact that crime has increased in a greater proportion in the North and Northeast regions of Brazil, are indications that crime will hardly stop growing until there is a change in the social structure of these regions.

The decomposition of criminality is still not widely discussed in the literature, thus there are questions to be researched and answered in future works, particularly related to long-term policies, as well as specific initiatives to fight crime. Therefore, identifying how the dynamic choice process behaves in other categories of crimes, in addition to verifying if there is any type of contagion among the different types of crime, may be considered as future topics to further this analysis.

\section{References}

Aguirre, A. (1995). Uma introdução à análise espectral de séries temporais econômicas. Nova Economia, 5(1), 41-60.

Araújo Junior, A. F., \& Fajnzylber, P. (2001). O que causa a criminalidade violenta no Brasil? Uma análise a partir do modelo econômico do crime: 1981 a 1996. Belo Horizonte: Universidade Federal de Minas Gerais, CEDEPLAR. Texto de Discussão, 162, 1-88.

At, C., \& Chappe, N. (2005). Crime timing. Economics Bulletin, 11(2), 1-7. http://dx.doi.org/10.2139/ssrn.558243

Becker, G. S. (1968). Crime and punishment: An economic approach (pp. 13-68). In the economic dimensions of crime. Palgrave Macmillan, London. https://doi.org/10.1007/978-1-349-62853-7_2

Elliott, D. S., Ageton, S. S., \& Huizinga, D. (1982). Explaining delinquency and drug use. Behavioral Research Inst, 1-190.

Engelen, P. J. (2004). Criminal behavior: A real option approach with an application to restricting illegal insider trading. European Journal of Law and Economics, 17(3), 329-352. https://doi.org/10.1023/B:EJLE.0000028640.24757.5d

Fajnzylber, P., Lederman, D., \& Loayza, N. (1998). Determinants of crime rates in Latin America and the world: An empirical assessment. World Bank Books, 1-31. https://doi.org/10.1596/0-8213-4240-1

Gottfredson, M., \& Hirschi, T. (1986). The true value of lambda would appear to be zero: An essay on career criminals, criminal careers, selective incapacitation, cohort studies, and related topics. Criminology, 24(2), 213-234. https://doi.org/10.1111/j.1745-9125.1986.tb01494.x

Gramckow, H. P., Greene, J., Marshall, I., \& Barão, L. (2016). Crime, Poverty and the Police. Addressing the Enforcement Gap to Counter Crime: Investing in Public Safety, the Rule of Law and Local Development in Poor Neighborhoods. International Bank for Reconstruction and Development of the World Bank, 1-46. https://doi.org/10.1596/24415

Huang, N. E., Shen, Z., Long, S. R., Wu, M. C., Shih, H. H., Zheng, Q., \& Liu, H. H. (1998). The empirical mode decomposition and the Hilbert spectrum for nonlinear and non-stationary time series analysis. Proceedings of the Royal Society of London. Series A: Mathematical, Physical and Engineering Sciences, 454(1971), 903-995. https://doi.org/10.1098/rspa.1998.0193

Justus, M., Kahn, T., \& Cerqueira, D. O. (2016). Mistério de São Paulo e o papel do PCC na redução de homicídios nos anos 2000. Instituto de Economia UNICAMP, 1-18.

Kim, D., \& Oh, H. S. (2009). EMD: A package for empirical mode decomposition and Hilbert spectrum. The $R$ Journal, 1(1), 40-46. https://doi.org/10.32614/RJ-2009-002

Kožić, I., \& Sever, I. (2014). Measuring business cycles: Empirical Mode Decomposition of economic time series. Economics Letters, 123(3), 287-290. https://doi.org/10.1016/j.econlet.2014.03.009

Lee, D. S., \& McCrary, J. (2017). The Deterrence Effect of Prison: Dynamic Theory and Evidence, Regression Discontinuity Designs (Advances in Econometrics, Vol. 38, pp. 73-146), Emerald Publishing Limited. https://doi.org/10.1108/S0731-905320170000038005

Leung, S. F. (1995). Dynamic deterrence theory. Economica, 65-87. https://doi.org/10.2307/2554776

Levitt, S. D. (1995). Using electoral cycles in police hiring to estimate the effect of policeon crime. National 
Bureau of Economic Research, 1-29. https://doi.org/10.3386/w4991

Lisboa, M. D. B., \& Andrade, M. V. (2000). Desesperança de vida: Homicídio em Minas Gerais, Rio de Janeiro e São Paulo: 1981 a 1997, 1-53.

Lott Jr, J. R. (1992). Do we punish high income criminals too heavily? Economic Inquiry, 30(4), $583-608$. https://doi.org/10.1111/j.1465-7295.1992.tb01283.x

Mocan, H. N., Billups, S. C., \& Overland, J. (2005). A dynamic model of differential human capital and criminal activity. Economica, 72(288), 655-681. https://doi.org/10.1111/j.1468-0335.2005.00437.x

O'Flaherty, B. (1998). Why repeated criminal opportunities matter: A dynamic stochastic analysis of criminal decision making. Journal of Law, Economics, \& Organization, 232-255. https://doi.org/10.1093/jleo/14.2.232

Oliveira, C. A. (2012). A real options approach to criminal careers. The Latin American and Iberian Journal of Law and Economics.

Preston, S. H. (1982). Relations between individual life cycles and population characteristics. American Sociological Review, 253-264. https://doi.org/10.2307/2094967

Resende, J. P. D., \& Andrade, M. V. (2011). Crime social, castigo social: desigualdade de renda e taxas de criminalidade nos grandes municípios brasileiros. Estudos Econômicos (São Paulo), 41(1), 173-195. https://doi.org/10.1590/S0101-41612011000100007.

Santos, C., \& Castelar, I. (2016). Avaliando as medidas de núcleo da inflação no Brasil. Economia Aplicada, 20(1), 35-56. https://doi.org/10.11606/1413-8050/ea134823

Santos, M. J. (2009). Dinâmica temporal da criminalidade: Mais evidências sobre o efeito inércia nas taxas de crimes letais nos estados brasileiros. Revista Economia, 10, 169-194.

Soares, R. R., \& Naritomi, J. (2010). Understanding high crime rates in Latin America: The role of social and policy factors. In the economics of crime: Lessons for and from Latin America (pp. 19-55). University of Chicago Press. https://doi.org/10.7208/chicago/9780226153766.003.0002

\section{Copyrights}

Copyright for this article is retained by the author(s), with first publication rights granted to the journal.

This is an open-access article distributed under the terms and conditions of the Creative Commons Attribution license (http://creativecommons.org/licenses/by/4.0/). 